\title{
Kitap Değerlendirmesi: Wilkinson, Taraneh Rosanna. Dialectical Encounters: Contemporary Turkish Muslim Thought in Dialogue. (Edinburgh: Edinburgh University Press, 2019), s. 269,
} ISBN: 978-1-4744-4153-7

\section{Adem Irmak ${ }^{1}$ (1)}

Türkiye Cumhuriyeti'nin kuruluşundan beri ilahiyat sahasındaki araştırmalar birtakım zorluklara ve kırılmalara rağmen üniversitede var oldu. Bu yazı Türkiye' de dini düşüncenin ve teolojinin akademik olarak nasıl ele alındığını, bir yanı Batılı, diğer yanı Doğulu modern Türk ilahiyatçısının durumunu ve Türk İslam düşüncesiyle Batı teolojisi arasında kurulmakta olan diyaloğu tartışan Taraneh R. Wilkinson'ın Dialectical Encounters: Contemporary Turkish Muslim Thought in Dialogue adlı eserini tanıtmayı ve değerlendirmeyi hedeflemektedir. Eser Türkiye'deki İlahiyat fakültelerinin genel durumuyla bu kurumların batıdaki teoloji çalışmalarıyla kurmaya çalıştıkları diyaloğu Türk ilahiyat camiasının iki önemli ismi üzerinden tartışır. Bunlardan biri Din Felsefesi sahasının üretken kalemlerinden Recep Alpyağıl, diğeri ise Kelam'a dair önemli çalışmaları tanınan Şaban Ali Düzgün'dür.

Eser, her bölümü iki başl1ktan oluşan 4 ana başl1k, kaynakça ve indeksten müteşekkildir.

“Giriş: Türk Müslüman “Teoloji” ve Türkiye’ de Din” başl1klı bölümde Wilkinson, Türk Müslüman teolojisi isimlendirmesiyle Türkiye'deki İlahiyat fakültelerindeki akademik çabayı ve ilahiyat fakültelerini kastettiğini belirtir. Yazar, İlahiyat fakültelerindeki çalışmaların modernizmle birlikte Batı Hristiyan teolojisi için de sorun olan "otorite, ateizm, kuşkuculuk, dini çoğulculuk” gibi meseleler üzerine yoğunlaştı̆̆ının farkındadır. (s. 3)

Wilkinson'ın bu çalışması Türk ilahiyatının son yirmi yılına yoğunlaşmaktadır. Yazara göre Türk ilahiyatındaki akademik çabanın değerinin tam anlaşılabilmesi, öncelikle Batı'daki felsefi ve dini düşünceye dair hasılanın farkında olunmasına bağlıdır. Bunun

1 Sorumlu Yazar: Adem Irmak (Arş. Gör.), İstanbul Üniversitesi, Illahiyat Fakültesi, Din Felsefesi Ana Bilim Dalı, İstanbul, Türkiye. E-posta: ademirmak@istanbul.edu.tr ORCID: 0000-0003-3610-4525

Atf: Irmak, Adem. "Dialectical Encounters: Contemporary Turkish Muslim Thought in Dialogue." Taraneh Rosanna Wilkinson'ın Dialectical Encounters: Contemporary Turkish Muslim Thought in Dialogue adlı eserinin tanıtımı. darulfunun ilahiyat 30, 2 (2019): 549-556.

https://doi.org/10.26650/di.2019.30.2.0066 
yanı sıra yerel pek çok unsur da ilahiyat çalışmalarında önemli bir rol oynar. İlahiyata yönelik araştırmalarda Türk ilahiyatının Batı, klasik İslam ve Türk-Osmanlı düşünce geleneklerinin sentezi olduğu gerçeğinin dikkate alınması gerekir. $\mathrm{Bu}$, hem otoritenin 'kim'liği hem de ilahiyatçının kimlerle, nasıl bir diyalog kurduğuyla ilgilidir. (s. 14-17)

Giriş bölümünün "Kökler ve Otoriteler: Diğer Otoriteler Işı̆̆ında Yenilikçi ve Ankara Paradigmalarını Yeniden Konumlandırmak" isimli başlığında Wilkinson, kendinden önce Türk ilahiyatı üzerine araştırmaları olan Felix Körner ve Philip C. Dorroll'un çalışmalarını değerlendirerek kendi pozisyonunu kurmaya çalışır. $\mathrm{Bu}$ iki ismin Türk ilahiyatçılarını -modernizm karşısındaki tavırlarına göre- yenilikçi veya modernist olarak sınıflandırmasını indirgemeci yaklaşımın bir sonucu gören yazar, daha nitelikli ve kullanışı bir tasnifin ilahiyatçıların entelektüel otorite karşısındaki tavırlarını da dikkate alan üçlü bir şemayla mümkün olduğuna inanır. Wilkonson, bu üçlü diyalektik şemayı, politik ve seküler bir bağlamdan ziyade Türk akademisindeki çalışmalara kaynaklık eden (b)ilim havzalarına göre kurgulamıştır. Yazarın bu şeması Türk ilahiyat akademisinin Batılı teolojik kaynakları, klasik ve modern Arap-İslam kaynakları ve Türk-Osmanlı kaynaklarından beslenen üçlü bir sac ayağına sahiptir (s. 5). Bu arada kendisinden önceki çalışmaların Türkçe bilmeyen okuyucu açısından oldukça ehemmiyetli olduğunu belirten yazar, bu iki isim dışında Avrupa ve Amerika'da bu konuyu ele alan pek fazla çalışmaya rastlanmadığını da söyler. (s. 29)

"Diyalektik Süreklilikte Birey ve Otorite" adlı bölümün ilk başlığı "Kurucu Metinler Açısından Alpyağıl Örneğị"dir. Modernizm ve Batılılaşmanın ürettiği sorunlarla karşılaşan Türk ilahiyatının bu durumla baş etmesinin yolu, bunlarla kuracağ 1 ilişkiyi kurucu metinler ve otorite bağlamında yeniden düşünmesidir. Modern ilahiyatçının kavram haritasını oluştururken kaynaklardaki farklılıktan ötürü otantiklik meselesiyle karşılaş̧ı̆̆ını düşünen Wilkinson, bunu Alpyağıl üzerinden çözümlemeye çalışır. Wilkinson'a göre, Alpyağıl otantik din felsefesi arayışındadır ve o eski dikotomilere takılmak yerine farklı kurucu metinleri kullanarak yeni bir din felsefesi önerir. Ona göre Alpyağ1l, Türk Müslüman kurucu metinleriyle sürekliliği devam ettiren ve bunu geleceğe taşıma kaygısı olan otantik/sahici felsefenin bireysel düzlemdeki imkanına inanmaktadır. (s. 66-67)

Wilkinson Alpyağıl'ın temel argümanının “Avrupa ve İngilizce konuşulan dünya, felsefe yaparken dini kökenleriyle hareket edilebiliyorsa Türkiye'de benzeri bir çaba neden olmasın?" sorusu olduğunu söyler. Alpyağıl'a göre otantiklik anda yaşayan, geçmişle bağları olan geleceği de yaratıcı bir şekilde kurma potansiyeli olan bir terimdir. (s. 71) Bu anlamıyla otantiklik kavramının köklerle doğrudan 
bir ilişkisi söz konusudur. Oysa bugünkü din felsefesi disiplini köken itibariyle daha çok Batılıdır. Alpyağıl ise daha sahici bir din felsefesi talebinin Osmanlı ve İslam kaynaklarını etkin kullanmayı öncelemesi gerektiğini düşünmektedir. (s. 72) Wilkinson'a göre Alpyağıl bunu yaparken Batılı kaynakları göz ardı etmez. (s. 73) Alpyağıl'ın oryantalizm ve bazı başka gerekçelerle Osmanlı' da bir felsefe geleneğinin olmadığını düşünen Türk ilim adamlarına karşı çıtığı husus, onların doğru sorular sor(a)mamasıdır. "Osmanlı' da otantik bir felsefe var mıydı?" sorusu yerine "Osmanlı hangi türden bir felsefe eyleminde bulundu?" sorusu üzerine düşünülmelidir. (s. 74) Şayet bu soru odak kabul edilirse yeni cevaplar bulunabilir ve 'gelen-ek'e eklemlenmekten bahsedilebilir.

Wilkinson, Türkiye'de otantik felsefe arayışında olan Alpyağıl'ın Ricoeur gibi Batılı bir felsefeciyi tercih etmisini ayrıca tartışmaktadır. Ona göre Alpyağıl'ın kurgusu oldukça anlamlıdır, zira Ricoeur'e göre bir meselede felsefi düşünmek, aynı zamanda o meseleyi dini düşünmektir. Ricoeur'ün felsefe, hermönetik ve teoloji arasında kaldırdığı duvarlar veya kurduğu köprüler, Alpyağıl'a göre din felsefesince de yapılabilir. (s. 75) Türk düşünce dünyasındaki krizi ve kırılmayı aşmak için Alpyağıl, otantik bir felsefenin ihtiyacı olan yeni konular ve yeni ufuklar arayışındadır. Bunlara Türk felsefecisini ulaştıracak olansa kurucu metinlerle alakalı kapsayıcı bakış açısına sahip ve hasılasında bulunan kapsamlı ve zengin kaynakların farkında olmasıdır.

Wilkinson, Türkiye'de felsefe yapma iddiasındaki kimi isimlerin dini kaynakların felsefe eyleminde kullanımına ilişkin çifte standart geliştirdiğini belirten Alpyağıl'ın bunun üstesinden gelebilmek için "abese irca" yöntemini kullandığını söyler. Batı felsefecilerinin Yahudi-Hıristiyan geleneğini halen kaynak olarak kullanmalarına karşın Türkiye'deki dini literatürü ihmal eden tavrın varlığını devam ettirmesini tuhaf bulan Alpyağıl, "sırf dini kaynakları kullanıyorlar diye Aquinas, Augustine, İbn-i Arabi, İbn-i Sina gibi isimlerin çabasına felsefe demeyecek miyiz?" sorusunu sorar. Ona göre sahici felsefe yapmanın yolu esas itibariyle dinden geçer. Felsefe yapmanın metoduna ise felsefeci karar vermelidir. (s. 77-78) Bu anlamda Alpyağıl'ın bir felsefeci olarak yaptığ ş̧ey; ya ... ya da ... şeklindeki dikotomiden uzak durmak ve hem... hem de... şeklinde, indirgemeci olmadan ve farklı olasılıklara açık düşünmektir. (s. 79) Bu da beraberinde hem dindarca hem de felsefi düşünebilen bireyin düşünsel eylemine yol açacaktır. Bu şekilde kendi kökenleriyle barışık, şimdiyi doğru kurgulayan ve geleceğe dair yeni bir felsefi yaklaşım sunabilecek otantik felsefenin mümkün olduğu görülecektir. Bu bağlamda felsefecinin içerisinden çıktığı tarih, anlatı, yaklaşım ve dilin onun felsefe yapış tarzını belirlediği dahi söylenebilir. Türk felsefesinin içerisine girdiği kriz ve yaşadığı kırılma aynı zamanda onun daha sahici bir felsefe yapmasının imkanını da içerisinde barındırmaktadır. 
Alpyağıl bunu Ricouer gibi zıt kutupları bir araya getiren kişiyi örnekleyerek yapar. (s. 81)

Bu bölümün ardından Wilkinson, Alpyağıl üzerine yaptığı çalışmaya onun Türk/ Osmanlı felsefesinin kurucu metinlerinin otantikliğini pratikte nasıl gösterdiğine ilişkin vaadiyle devam eder. Bu bölümün "Tazammunlar ve Bireyin Rolü" başlı̆̆ındaysa yazar, "otantik" in çağrıştırdığı kavramlar olan anlat1, tarih ve geçmişle kurulan hipoleptik süreklilikten kastın ne olduğu ve kapsayıcı kurucu metinlerin neyi zorunlu kıldığını tartışmaktadır. Wilkinson, Alpyağıl'ın çabasını "restorasyon, entegrasyon ve yeniden anlatı" olarak görür. (s. 93) Wilkinson, ancak yetkili ve hipoleptik uyanıklığa sahip bireyin Türkiye'ye miras kalan entelektüel otoritenin karmaşık kurucu metinlerinin sebep olduğu kaosa cevap bulabileceğini ileri sürer. Alpyağıl ise bu anlamda, hem farklı ilim havzalarının Türk ilahiyatı içerisinde diyalektik karşılaşmaya girebileceğine olan inancından, hem de kurucu metinlerin otoritesinin halihazırda canlılığı devam ettiren geleneğe sağladığı imkanlara dair farkındalığından ötürü bu kitap için seçilmiş iyi bir örnektir.

Kitabın ikinci bölümü olan "Yetkilendirmenin Teolojik Antropolojisi”, "Özgürlük Dini Açısından Düzgün'ün Örnek Olay Oluşu” ve "Beşerî Faillik, Sorumluluk ve Tevhit" alt başlıklarından oluşur. Bu bölümün ilk başlı̆̆ında daha ziyade bireysel düzlemde otorite meselesini ele alacağını belirten Wilkinson, Düzgün'ün teolojik antropoloji tezini kendi iddiasını sınanmak için kullanır. Ona göre Düzgün, tıpk1 Alpyağıl gibi birden fazla ilmi havzadan beslenir. İslam ve Batı, din ve sekülerlik, gelenek ve modernizm gibi ikili ayrımlardan ziyade bireysel failliği olumlayan ve tanımlayan biridir. (s. 127) Bu bölümde Wilkinson Düzgün'ün temel tezlerini, onun modernizm karşısındaki tutumunu ve teolojik antropolojisini tartışırken, Batı ve Osmanl-Türk kaynaklarının yanı sıra İran ve Hint coğrafyasından da beslendiğini ve temelde Avrupa Aydınlanmasının temin ettiği değerler ve kavramlarla konuştuğunu belirtir. (s. 129) Kendisini evrenselci olarak tanımlayan Düzgün'ün insanın fitrat, akıl ve doğru dini arayışından dolayı -bireyin sorumluluğu bağlamında- İslami ve Aydınlanmacı değerlerin uyumundan bahsettiğini söyler. Birey, kendisinde bulunan vicdan, akı1, fitrat ve sağduyu sayesinde ilahi olanı, doğalı ve evrensel değerleri keşfedebilir. Din ise bu evrensel ilke ve değerleri toplumlara hatırlatmak ve bu çerçevede toplumu yeniden kurmayı arzular. Wilkinson için Düzgün'ün din tanımı ve dine biçtiği rol oldukça 'modern'dir. Ancak modern kavramlarla konuşan Düzgün için farklı modernlik tanımları vardır; günümüz Batı modernliği, insanlığ 1 homojenleştirme arzusunda olan tehlikeli bir modernliktir. Batı modernizminin dayatmalarından kurtulmanın yolu, bireyin dini otoritesi üzerine vurgu yapmaktan ve dünyadaki rolünü doğru anlamaktan geçer. Bu tavra Düzgün, "İslami antropolojik teoloji” der; bu anlayış da insanın evrensel bir ahlakının oluşuna, insan yaşamının 
çokluğuna dair İslami bir doğrulamaya, dinin hem yapıcı hem yıkıcı rolü olduğunu kabule, dinin temelde modernleştiren bir yapı olduğu iddiasına ve insanın fail oluşuyla Tanrı'nın fail oluşu arasında çekişmenin olmadığı görüşüne dayanır. (s. 132) Onun İslami antropolojik teolojisini derinlemesine irdeleyen Wilkinson, modernizm karşısında indirgemeci olmayan çoğulcu bakış açısına sahip olduğunu belirtir. (s. 132-39)

Bu bölümün ikinci başlığında Wilkinson, "dinin değerin kaynağı oluşu, din, birey ve çoğulculuğun tevhidi çerçevesi” üzerinden Düzgün'ün düşüncesini irdeler. Düzgün'e göre din, yaratılmış olanda bulunan tüm değerin ve anlamın belirdiği bir gerçeklik olmanın yanında beşerin sayesinde özgürleştiği bir olgudur. Doğru din; dışlayıcı olmayan, kuşatıcı bir yapıdır. Onun için mevcut dinler içerisinde en kapsayıcısı İslam'dır. Zira ona göre Kur'an, dinin özü olarak insanlığın hayrına işler yapmayı öğütler. (s. 163) Düzgün açısından dinin eşit, adil, saygı çerçevesinde bir yaşam tasarlaması, inanlarının eleştirel, yaratıcı, diyalektikle düşünmeleri ve diğer din mensuplarıyla inananları arasında nasıl bir ilişki tesis ettiği onun doğruluğunun kıstaslarıdır; bunları en iyi şekilde İslam karşılar. (s. 164) Vakıada yaşanan İslam'la ideal İslam arasında da bir ayrıma giden Düzgün, yaşanan İslam'ın şekillenmesinde toplumsal realitelerin belirleyici olduğunu düşünür. (s. 165) Bireyin din ve medeniyet için çok önemli olduğunu hatta bunların temeli olduğunu belirten Düzgün, beşerin eylemlerinde özgür olmasının zorunluluğuna inanır. Beşerin tercihi toplumu geliştiren ve dönüştüren bir vakıadır. Beşer hem halife olması hasebiyle hem de ihtilaf içerisinde yaratılmış olması sebebiyle sorumluluk bilinci sayesinde kendisine yabancılaşmayacaktır. Kendisine yabancılaşmayan bu birey dinin yeniden kurucu işlevini de gözlemleyecektir. (s. 170)

Çokluğun tevhidi çerçevesiyle alakalı olarak Wilkinson, Düzgün'ün beşerî değerler ve çağdaş bazı meselelerle İslam'ın temel ilkesi tevhidi nasıl bağdaştırdığını tartışır. O, Düzgün'ün “Tanrı'nın birliğini tasdik etmek aynı zamanda insanın çokluğunu deklare etmektir” şeklindeki düşüncesi perspektifinde bu durumu değerlendirir. Yani çokluğun tevhidi, Allah dışındaki her şeyde çokluğun olduğunu belirtmektir. Tevhit üzere olmak gönüllü bir şekilde Allah'a teslim olmaktır. Allah'ın tek olduğunu kabul etmek onun ahlaki olarak zorunlu olduğunu kabul etmek ve kendi dışında olanlardan tamamen farklı olduğunu belirtmektir. (s. 173) Tanrı'nın tek bir tarih kurgulamaya izin vermediğini, aksi durumda bunun bir hegemonya ve tekel oluşturacağını düşünen Düzgün, Allah'ın bir olduğuna inancın aynı zamanda O’nun dışında var olan her şeyde çoğulculuğu savunmayı gerektirdiğini ifade eder.

Wilkinson, Düzgün'ün de tıpk1 Alpyağıl gibi çeşitli geleneklerden ve kaynaklardan kurguladığı düşüncesini okuyucusuna sunarken modernizm karşısında sergilenecek 
tavrın indirgemeci ve dışlayıcı değil bireyin inisiyatifini önceleyen, kuşatıcı ve canlı bir tavır olması gerektiğine inandığını ifade eder. Düzgün'ün modern ve geleneksel değerlerin entegrasyonunda Batılı ve İslami kaynakları birlikte kullanmaktan çekinmediğini belirten yazar, onun da dikotomilere takılmak yerine Arap-İslam, Türk ve Batılı entelektüel kaynakları kullandığını söyler.

Kitabın son bölümünün "Diyalektikten Doğruca Adrese: Türk İlahiyatçıların Diğer Dinler ve Ateizm Üzerine Görüşleri” başlı̆̆ında yazar, Türk ilahiyatçılarına göre deizm, skeptisizm ve inançsızlık gibi meselelerin Batı'daki krizin bir neticesi olarak Hristiyanlıktan kaynaklandığını düşünmektedir. Wilkinson, onlara göre onto-teolojinin Batı'da yaşadığı krizin İslami perspektifle bakıldığında sorun oluşturmadığını belirtir; hatta Türk İlahiyat literatüründe metafiziğin tanrısının oldukça canlı olarak tartışıldığına dair hatırı sayılır örnekler de verir. Bunun yanı sıra ateizmin dahi Hristiyanlığın ürünü olduğunu düşünen Türk ilahiyatçılarının bulunduğunu da ifade eder. (s. 190) Bunlardan İbrahim Çoşkun, ateizmin doğrudan Hristiyanlık’tan kaynaklandığını söylemesine karşın, Düzgün Hristiyan entelektüel tarihinde yolunda gitmeyen durumları tespite uğraşır. Ona göre Batı'da işlerin karmaşı hale gelmesinin altında vahiy ve akıl, bilim ve din arasında ilişkinin sorunlu olması yatmaktadır. Düzgün, bu krizi aşmanın yolu olarak ise ontoloji tabanlı bir sistem yerine ahlaka dayalı bir yapı önerir. İnanç ve inançsızlık meselesini tartışırken de Wilkinson, Düzgün'ün üçlü diyalektik şemaya uygun bir şekilde klasik İslam ve Batı kaynaklarını birlikte kullandığını ifade eder. Deizm söz konusu olduğunda Türk ilahiyatının bunu ateizmden önceki aşama olarak gördüğünü, ancak istisnai bir görüş olarak Y. Nuri Öztürk'ün deizmi olumlu bir Tanrı tasavvuru olarak algıladığını söyleyen Wilkinson, onun yapmış olduğu çalışmaların Batı ve İslam kaynaklarıyla girilen bir diyalektikten ziyade dinin Kemalist bir okuması olduğunu da belirtir.

Bu başlık altında ele alınan bir diğer konu da kuşkuculuktur. Bu bölümde yazar, Mehmet Bayraktar'ın Pascal Oyunu: Hz. Ali, Gazali ve Pascal'a göre Ahiret'e Zar Atmak isimli çalışmasını ele alır. Ona göre Bayraktar, Hristiyanlık savunusunda Pascal'ın ileri sürdüğü kuramı, Gazali'nin daha önce önerdiğini ifade etmekte ve böylece İslam düşünce geleneğinin Hristiyanlığ1 etkilediğini belirtmektedir. Yazar, kuşkuculuğu sahih iman için ciddi bir meydan okuma olarak kabul etmeyen Bayraktar'ın bu tavrının konuyla ilgilenen ilahiyatçıların hemen hemen ortak kanısı olduğunu dile getirir. Ancak bu noktada Alpyağıl'ın istisna olduğunu söyleyen Wilkinson, onun bu meydan okumayı ciddiye aldığını düşünür.

Bu bölümün bir diğer konusu, belki de bu çalışmanın yapılma gerekçesi olan çoğulculuk meselesidir. Yazar, "Çoğulculuk inancın mı yoksa kuşkuculuğun mu 
yakıtı?" sorusuyla başladığı bu bölüme örnek olarak dini çoğulculuk bağlamında Mahmut Aydın'1 ve kapsayıcılık bağlamındaysa Adnan Aslan'1 zikreder. Zira bunun sebebi mezkûr isimlerin kendilerini öyle takdim etmesidir. Yazar, bu isimlerin de, incelediği önceki düşünürler gibi Batıyla girmiş oldukları diyalektik karşılaşmada Batılı kaynaklarla İslami kaynakları başarılı şekilde kullandığını ifade eder. Ateizm, kuşkuculuk, deizm, dini çoğulculukla alakalı Türkiye'deki çalışmaların ortak yan1, söz konusu meseleleri doğrudan Hristiyanlıkla ilişkilendirmeleridir. Öztürk ve Alpyağıl bu meselelerin Hristiyanlık için problem olduğu kadar İslam için de problem olacağ 1 kanısındadır.

Eserin “Sonuç: Türk İslam'1, Modernizm ve Diyalog Üzerine Düşünceler" kısmı yazarın yaptığ modernizme karşı sunabileceği cevaplar ve Batı akademisinin Türk ilahiyatıyla gireceği diyaloğun keyfiyetine ilişkin öngörülerde bulunmaktadır.

Wilkinson'ın bu çalışması Türk ilahiyat akademisinin son yirmi yılına dair oldukça başarılı sayılacak bir fotoğraf ortaya koymaktadır. Yazarın Türk ilahiyat akademisinin özellikle de din felsefesi, kelam, dinler tarihi gibi alanlarında derinlemesine bir okuma yaptığı hem eserin kaynakçası hem de Türk akademisinin kaynaklarını tespit ederken yaptığı değerlendirmelerde kendini belli etmektedir. Wilkinson'ın önerdiği üçlü diyalektik şeması, ilahiyat sahasının emek işçileri için ve ilahiyata dair çalışmayı düşünenler için iyi bir perspektif sunabilir. Zira Türk ilahiyatına dayatılan dikotomilerden kurtulmak ve yeni ufuklara doğru yol alabilmek ancak alternatifleri çoğaltmakla mümkün olabilir. Bilindiği üzere din ve devlet, din ve sanat, din ve akıl gibi ayrımlarda sanki bu iki unsur birbirinin karşıtıymış gibi okutuldu ve öğretildi. Ancak Alpyağıl'ın “vavlı düşünmek” dediği, “ve” bağlacının alternatif anlamları olduğu gerçeği iskalandı. Bu anlamda diyalektik karşılaşmaların faydasına inanan bir akademisyen olarak Wilkinson'ın Batı modernizmi karşısında Türkiye'deki ilahiyat fakültelerinin ve ilahiyatçıların Batı akademisiyle gireceği diyaloğun doğasına dair bu çalışması, Batı'da dini düşünce sahasında çalışan ve Türkçe bilmeyen okuyucuya Türk ilahiyatını tanıtacak nitelikli bir içeriğe sahiptir. Öte yandan Türk ilahiyatına kendi krizlerini aşmasında yardımcı olacak zengin bir kaynak ve muhatap kitlesine sahip olduğunu göstermesi bakımından da oldukça önemli değerlendirmeler içermektedir. Diğer deyişle Wilkinson, Türk ilahiyat akademisinin Batı' daki görünürlüğüne olumlu bir katkı sunmanın yanı sıra diyalektik karşılaşmaların yeni imkanlar doğurabileceğini de göstermeye çalışmışır. Ayrıca yazar, kendisi gibi iki ayrı dünya arasında köprüler kurma amacında olan Türk ilahiyatçılarının modernizm karşısındaki tutumlarını okuyucuyla buluşturmaktadır. Wilkinson'ın eserinde yer verdiği ilahiyatçıların modernizme yönelik cevaplarını incelerken kullandığ 1 üçlü diyalektik şemanın hizmet ettiği önemli bir husus ize 
Türk-Müslüman perspektifiyle Hristiyan Batı perspektifi arasındaki karşılaştırmayı kolaylaştırmaktır.

Sonuç itibariyle eser, Türkçe bilmeyen Batılı filozof ve teologlara Türk ilahiyat akademisini tanıtan, Türk ilahiyatçısına da kendisinin dışardan nasıl göründüğünü gösteren önemli bir çalışmadır. Wilkinson'ın son cümlesiyle bu yazıyı bitirecek olursak "diyalektik karşılaşmalar süregiden karşılıklı konuşmalardır" (s. 242); evrensel ve entelektüel anlamda akademik çaba da varlığını bu diyalektiğe borçlu olabilir. 